\title{
PERENCANAAN ANALISA PEMELIHARAAN MESIN MENGGUNAKAN PENDEKATAN MARKOV CHAIN di PT. CARDSINDO TIGA PERKASA
}

\author{
Adi Candra \\ Dosen Program Studi Teknik Industri, Fakultas Teknik Universitas Pamulang \\ dosen01304@unpam.ac.id
}

\begin{abstract}
ABSTRAK
telah dilakukan penelitian tentang perencanaan analisa pemeliharaan mesin menggunakan pendekatan markov chain, untuk dmengurangi biaya perbaikan mesin dengan meinimalkan breakdown pada mesin atau peralatan di PT. Cardsindo Tiga Perkasa. Metode ini juga dapat menganalisa kejadian diwaktu yang akan datang secara matematis. Pada type mesin A yang berjumlah 2 mesin, diperlukan waktu 40 menit, untuk type mesin B yang berjumlah 4 mesin memerlukan 80 menit, dan pada type mesin $\mathrm{C}$ yang berjumlah 3 mesin memerlukan waktu sekitar 45 menit untuk tindakan perbaikan dalam satu bulan. Dapat disimpulkan bahwa penelitian dengan menggunakan metode markov chain didapatkan biaya penghematan untuk jenis mesin type A sebesar $44 \%$ dari cost pemeliharana sebelumnya, kemudian untuk meisn type B sebesar $69 \%$, dan untuk type mesin C sebesar $29 \%$ dari biaya maintenance perusahaan.
\end{abstract}

Kata Kunci : mesin, pemeliharaan, biaya, markovchain

\section{PENDAHULUAN}

Mesin merupakan salah satu aspek terpenting dalam bidang industri manufaktur maupun industri jasa karena mesin merupakan investasi yang memiliki nilai besar pada sebuah perusahaan manufaktur. Dalam kegiatan produksi, sangat diharapkan proses berlangsung secara lancar dan tanpa adanya hambatan yang berarti, oleh karenanya mesin harus berada pada kondisi dimana tingkat ketersediaan dan keandaalanya tinggi. Jika terdapat gangguan pada salah satu mesin maka kegiatan produksipun harus terhenti, sehingga produk yang dihasilkan tidak optimal dan menimbulkan kerugian bagi perusahaan, Kerusakan pada mesin dapat terjadi diantaranya ialah human error, terjadi kedaan darurat, kurangnya perawatan dan sebagainya. Untuk mengevaluasi kondisi mesin tersebut diperlukan suatu anlisis yang memungkinkan untuk meningkatkan produktifitas pada setiap mesin. Salah satu analisis yang biasa digunakan untuk menjaga tingkat keandalan mesin ialah Rantai Markov, Rantai Markov digunakan untuk menentukan peluang jangka panjang dari kondisi mesin tersebut.. Tingkat keandalan mesin yang rendah mengakibatkan kerugian bagi perusahaan dan kemungkinan membahayakan pekerja, sehingga diperlukan suatu pengukuran dan analisis tingkat keandalan atau reliabilitas suatu mesin untuk membantu perusahaan agar melakukan tindakan perawatan yang teratur.

Mesin yang digunakan pada perusahaan rata-rata berumur lima sampai enam tahun sesuai dengan karakteristik atau type mesin yang ada. Mesin atau peralatan produksi PT. Cardsindo mengalami kerusakan atau gangguan yang menyebabkan proses produksi terhenti, kenyataan yang ada di lapangan mesin atau peralatan baru akan dilakukan pemeliharan ketiak terjadi kerusakan, hal ini dapat mengakibatkan biaya kerusakan yang cukup tinggi dikarenakan kurang atau tidak adanya perencanaa pemeliharaan secara yang sitemati yang dilakukan. Berdasarkan masalah yang terjadi dialapangan peneliti mengusulkan agar dilakukan perencanaan pemrawatan mesin yanga da denagn Teknik atau metode markov chain yang diharapkan dengan metode tersebut dapat menurunkan biaya pemelihraan yang ada saat ini dengan sistematis. Faktor penyebab minimnya produktifitas suatu mesin ataupun peralatan dapat menimbulkan kerugan yang nyata bagi setiap perusahaan hal ini sisebabkan oleh kuranya efektifitas dan effisiensi pada suatu mesin ataupun peralatan ayang ada, terdapat enam kerugian yang menyebabkan efektifitas 
mesin dapat terganggun yang disebut dengan six Big Losses.

Dalam memproduksi produknya industry ini memiliki banyak mesin yang memiliki spesifikasi dan karakter yang berbeda. Intensitas pemakaian mesin yang lama menyebabkan performa mesin mengalami penurunan dan terkadang mesin mengalami masalah sehingga menghambat jalannya proses produksi. Belum optimalnya proses perawatan membuat tingginya nilai downtime dan proses perbaikan memakan waktu. Dari permasalahan tersebut maka dibuat usulan untuk melakukan penelitian guna menganalisa apakah pelaksanaan perawatan tersebut sudah maksimal, penelitian tersebut dapat diterapkan dengan menganalisa manajemen perawatan dengan penerapan metode Markov Chain.

\section{DASAR TEORI}

\section{A. Definisi pemeliharaan}

Tugas dan kegiatan pemeliharaan pada hakikatnya dilaksanakan untuk mempertahankan kondisi sistem produksi agar tetap bisa melaksanakan operasinya secara optimal. Dan tugas ini dapat menjadi prosedur dalam kegiatan maintenance. Dan sebelum memasuki pada tugas-tugasnya, terlebih dahulu mengartikan kegiatan maintenance.

Kegiatan pemeliharaan (Maintenance) ini memiliki beberapa kategori dan dua bagian pokok nya yaitu:

a.Bagian yang mengarah untuk mereduksi kerusakan, yang dilakukan dalam hal ini antara lain:

1) Pemeliharaan preventive;

2) Penyederhanaan pekerjaan operasional;

3) Suku cadang perawatan awal;

4) operator yang tepat terhadap instruksi.

b.Reduksi kegiatan yang berakibat pada kerusakan. beberapa yang harus diperhatikan antara lain:

1) Mempercepat penyelesaian atau melakukan akselerasi pelaksanaan operasional dan Melipat gandakan petugas

2) Tingkat kesulitan di minimalisasi;

3) Suku cadang yang selalu tersedia dan alternatif pada waktu operasional

\section{B.Prosedur perawatan}

Untuk setiap kelompok staf yang telah ditunjuk pada pemeliharaan cepat, efektif dan bebas kesalahan paling baik dicapai jika prosedur logis dan formal diikuti pada setiap kesempatan. Pendekatan sembarangan berdasarkan pendapat subyektif dari teknisi pemeliharaan, meskipun kadang-kadang menghasilkan jalan pintas yang spektakuler, tidak mungkin membuktikan metode yang lebih baik dalam jangka panjang. Prosedur formal juga memastikan bahwa kalibrasi dan pemeriksaan penting tidak dihilangkan, bahwa diagnosis selalu mengikuti urutan logis yang dirancang untuk mencegah deteksi kesalahan yang tidak benar atau tidak lengkap, bahwa alat uji yang benar digunakan untuk setiap tugas (kerusakan kemungkinan terjadi jika alat uji yang salah digunakan) dan bahwa praktik berbahaya dihindari. Prosedur perawatan yang benar dijamin hanya dengan manual yang akurat dan lengkap dan pelatihan menyeluruh.

\section{METODE DAN TEKNIK PENGUKURAN}

\section{A. Metode Markov Chain}

Markovchain merupakan Teknik matematis yang biasanya digunakan dalam melakukan pebuatan model bermacam macam sistem dan proses bisnis. Teknik ini dapat digunakan untuk memperkirakan perubahan-perubahan di waktu yang akan datang atas dasar perubahanperubahan di waktu yang lalu.

Matrik transisi satu langkah item-i yang merupakan pemeliharaan yang dilakukan oleh perusahaan adalah :

\begin{tabular}{|c|c|c|c|c|}
\hline $\mathbf{j}$ & $\mathbf{1}$ & $\mathbf{2}$ & $\mathbf{3}$ & $\mathbf{4}$ \\
\hline 1 & $\mathrm{P}_{11}$ & $\mathrm{P}_{12}$ & $\mathrm{P} 13$ & $\mathrm{P} 14$ \\
\hline 2 & 0 & $\mathrm{P}_{22}$ & $\mathrm{P}_{23}$ & $\mathrm{P}_{24}$ \\
\hline 3 & 0 & 1 & $\mathrm{P}_{33}$ & $\mathrm{P}_{34}$ \\
\hline 4 & $\mathrm{P}_{41}$ & 0 & 0 & 0 \\
\hline
\end{tabular}

Maka probabilitas transisi dari status i ke status j ini akan lebih mudah jika disusun dalam suatu bentuk matrik sebagai berikut

$$
[\pi 1 \pi 2 \pi 3 \pi 4]\left[\begin{array}{cccc}
P 11 & P 12 & P 13 & P 14 \\
0 & P 22 & P 23 & P 24 \\
0 & 0 & P 33 & P 34 \\
P 41 & 0 & 0 & 0
\end{array}\right]=[\pi 1 \pi 2 \pi 3
$$


Catatan : $\pi_{1}+\pi_{2}+\pi_{3}+\pi_{4}=1$

Maka akan di dapat persamaan sebagai berikut :

$\begin{array}{lll}\pi 1 & + & \pi 2 \\ & \pi 4 & =1\end{array} \quad+\quad \pi 3 \quad+$

$\mathrm{P} 11 \pi 1+\quad 0 \quad+\quad 0 \quad+$

$\mathrm{P} 41 \pi 4=\pi 1$

$\mathrm{P} 13 \pi 1+\mathrm{P} 23 \pi 2+\mathrm{P} 33 \pi 3+$

$\mathrm{P} 14 \pi 1+\mathrm{P} 24 \pi 2+\mathrm{P} 34 \pi 3+$ $0 \quad=\pi 4$

B. Analisis Biaya

Dalam menentukan biaya pemeliharaan disini meliputi preventif maintenance dan juga corrective maintenance yang dilakukan kettka mesin tidak beroperasi dan hanya menitikberatkan biaya pda saat downtime.

C. Biaya Down Time

Biaya ini merupkan biaya yang idtimbulkan akibat tidak beroperasinya suatu mesin .

D. Biaya Penyelenggaraan preventife maintennace

$\mathrm{C} 1 \mathrm{i}=$ Average Maintennace Time

E. Pencegahan $\mathrm{x}$ Biaya down time

Biaya Kerusakan (Pemeliharaan Korektif)

Jika biaya pemeliharaan korektif ini dilambangkan dengan $\mathrm{C} 2 \mathrm{i}$ untuk setiap item-i maka dapat dinyatakan

$\mathrm{C} 2 \mathrm{i}=$ Waktu rata-rata pemeliharaan perbaikan $\mathrm{x}$ Biaya down time

F. Ekspetasi Cost Average

Berdasarkan pada biaya-biaya pemeliharaan pencegahan dan korektif maka akan didapatkan biaya-biaya pemeliharaan untuk masing-masing item. Biaya ekspektasi ini disimbolkan dengan $\mathrm{E}(\mathrm{C})$.

\section{HASIL DAN PEMBAHASAN}

Berikut akan dipaparkan hasil dan pembahasana pada penelitian ini

\section{A. Jumlah mesin}

Tabel 1 jumlah mesin berdasarkan type mesin

\begin{tabular}{|c|c|c|}
\hline No & Type Mesin & Jumlah \\
\hline 1 & Type A & 2 mesin \\
\hline 2 & Type B & 4 mesin \\
\hline 3 & Type C & 3 mesin \\
\hline
\end{tabular}

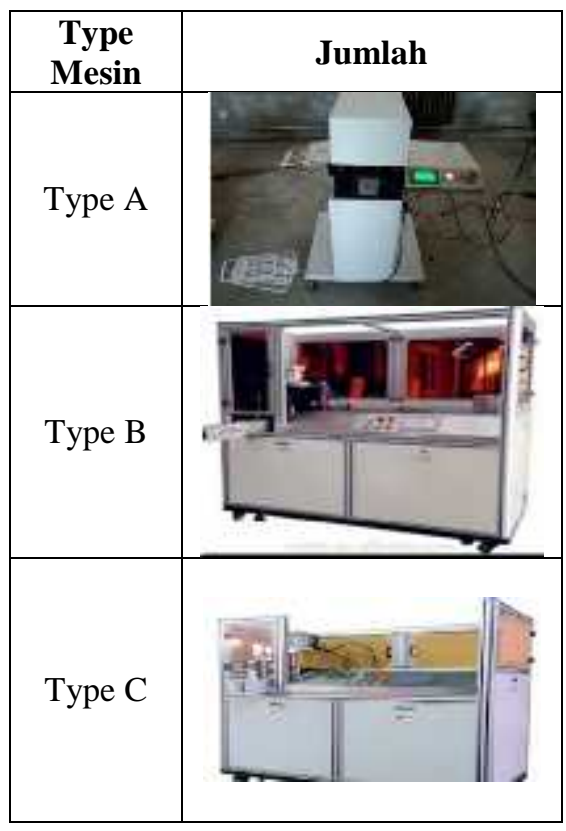

B. Data Waktu Pemeliharaan Preventif

Data waktu pemeliharan paad type mesin setiap bulan

\begin{tabular}{|c|c|c|c|c|c|c|}
\hline $\begin{array}{l}N \\
0\end{array}$ & $\begin{array}{c}\text { Meria } \\
\text { (2) }\end{array}$ & $\begin{array}{c}\text { Jasl } \\
\text { ah } \\
\text { (0) }\end{array}$ & $\begin{array}{c}\text { Walnz } \\
\text { Altait' } \\
\text { Bulan } \\
(4)\end{array}$ & $\begin{array}{c}\text { Toul } \\
\text { Taken } \\
\text { (Atexio Bdala } \\
\text { a) } \\
(5)=(3) x(0)\end{array}$ & $\begin{array}{c}\text { Tocal } \\
\text { Waken } \\
(\text { Jam Bulan } \\
\text { ) } \\
(0)=(5): 60\end{array}$ & $\begin{array}{c}\text { Toul } \\
\text { Whikr } \\
(f a=7 a b a \\
\text { a) } \\
(7)-(0) \times \\
12\end{array}$ \\
\hline$T$ & $T y p<A$ & 2 & 211 & 40 & 067 & sot \\
\hline 2 & Type B & 4 & 211 & 50 & 113 & $15 \%$ \\
\hline T & Typec & 3 & 15 & 45 & 0.5 & 9 \\
\hline
\end{tabular}

\section{Data Biaya Down Time}

Berikut disampaikan data biaya perbaiakn pemeliharan pada perusahaan

\begin{tabular}{|c|c|c|c|c|}
\hline No & $\begin{array}{c}\text { Jenis } \\
\text { Mesin }\end{array}$ & $\begin{array}{c}\text { Jumlah } \\
\text { Mesin }\end{array}$ & $\begin{array}{c}\text { Biaya } \\
\text { Down } \\
\text { time tiap } \\
\text { Mesin } \\
\text { (Rp/Jam) }\end{array}$ & $\begin{array}{c}\text { Biaya } \\
\text { Down } \\
\text { time } \\
\text { Total } \\
\text { (Rp) }\end{array}$ \\
\hline 1 & $\begin{array}{c}\text { Type } \\
\text { A }\end{array}$ & 2 & 345.450 & 690.900 \\
\hline 2 & $\begin{array}{c}\text { Type } \\
\text { B }\end{array}$ & 4 & 462.700 & 1.850 .800 \\
\hline 3 & Type & 3 & 586.350 & 1.759 .050 \\
\hline
\end{tabular}




\begin{tabular}{|l|l|l|l|l|}
\hline & $\mathrm{C}$ & & & \\
\hline
\end{tabular}

\section{Pengolahan Data}

Untuk menentukan peluang status akan ditentukan terlebih dahulu besarnya probabilitas trasnisi yang dapat dihitung berdasarkan proporsi jumlah masing masing satatus yang dialami, keudian dibuat matriks awal yang merupakan pemelhraan yang dilaksankan perusahaan.Berikut diuraikan hasilawal matrik :

Berdasarkan tabel probabilitas transisi meisn type A maka didapatkan nilai probabilitas dari kondisi mesin type A adalah:

a. Kondisi Baik

Kondisi baik ke baik : 0,841

Kondisi baik ke ringan : 0,082

Kondisi baik ke sedang: 0,02

Kondisi baik ke berat :0,055+

Total : 1,178

b. Kondisi Rusak Ringan

Kondisi ringan ke ringan : 0,069

Kondisi n ringan ke sedang $\quad: 0,167$

Kondisi ringan ke berat $\quad: 0,083$

Total : 0,319

c. Kondisi Rusak Sedang

Kondisi sedang ke sedang $\quad: 0,25$

Kondisi sedang ke berat $\quad: 0,083$

Total

: 0,333

d. Kondisi Rusak Berat

Kondisi berat ke baik $\quad: 0,25$

Beirikut matrik mesin type A yang didapatkan dari data diatas

\begin{tabular}{|c|c|c|c|c|}
\hline $\mathbf{j}$ & $\mathbf{1}$ & $\mathbf{2}$ & $\mathbf{3}$ & $\mathbf{4}$ \\
\hline 1 & 0,841 & 0,082 & 0,020 & 0,055 \\
\hline 2 & 0 & 0,069 & 0,167 & 0,083 \\
\hline 3 & 0 & 0 & 0,25 & 0,083 \\
\hline 4 & 0,25 & 0 & 0 & 0 \\
\hline
\end{tabular}

Berikut matrik mesin type $B$ yang didapatkan perhitungan transisis probabilitas

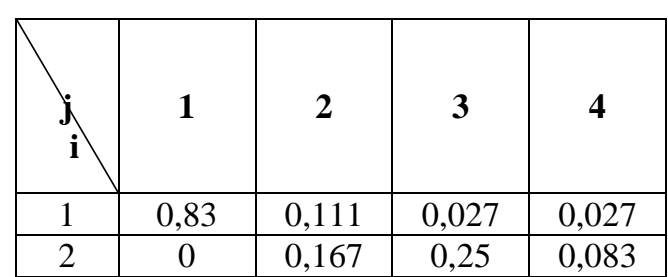

\begin{tabular}{|c|c|c|c|c|}
\hline 3 & 0 & 0 & 0,33 & 0,167 \\
\hline 4 & 0,083 & 0 & 0 & 0 \\
\hline \multicolumn{5}{|c|}{ Berikut matrik mesin type C yang }
\end{tabular}

didapatkan perhitungan transisis probabilitas

\begin{tabular}{|c|c|c|c|c|}
\hline $\mathbf{i}^{\mathbf{j}}$ & $\mathbf{1}$ & $\mathbf{2}$ & $\mathbf{3}$ & $\mathbf{4}$ \\
\hline 1 & & & & \\
\hline 2 & 0,847 & 0,083 & 0,041 & 0,027 \\
\hline 3 & 0 & 0,167 & 0,416 & 0,167 \\
\hline 4 & 0,083 & 0 & 0,33 & 0,167 \\
\hline
\end{tabular}

E. Peluang Status Mesin pada Keadaan Steady State

Berdasarkan analisa peluang terjadinya Failure sedang dan Failure berat dalam keadaan mapan (steady state) untuk jangka panjang pada setiap mesin adalah Sbb :

1) Mesin Type $A$

\begin{tabular}{|c|c|c|c|c|}
\hline \multirow[b]{2}{*}{$\begin{array}{l}\text { Kugistan } \\
\text { Permetibarasan }\end{array}$} & \multicolumn{4}{|c|}{ Prubabilitas } \\
\hline & $\begin{array}{l}\text { Galk } \\
(\pi 1)\end{array}$ & $\begin{array}{c}\text { Kennsikan } \\
\text { Rinavex } \\
(\pi 2)\end{array}$ & $\begin{array}{c}\text { Kernsakan } \\
\text { Sedang } \\
(\pi: 5)\end{array}$ & $\begin{array}{c}\text { Kmpusalean } \\
\text { Beras } \\
(\pi 4)\end{array}$ \\
\hline$P_{0}$ & 0,194 & 0,218 & 0,161 & 9619 \\
\hline P1 & 0,327 & 0.476 & ก.087 & $0,0<1$ \\
\hline$v_{2}$ & 0,004 & IIa:1 & $\| 101 /$ & $404:$ \\
\hline P1 & 0.815 & 0,057 & 0,017 & 0018 \\
\hline $\mathrm{P4}$ & $0 \leqslant 44$ & 0074 & $0.0 \geq 8$ & 0052 \\
\hline
\end{tabular}

2) Mesin Type B

\begin{tabular}{|c|c|c|c|c|}
\hline \multirow[b]{2}{*}{$\begin{array}{c}\text { Kegiztan } \\
\text { Pomeklitaraen }\end{array}$} & \multicolumn{4}{|c|}{ Probabilites } \\
\hline & $\begin{array}{l}\text { Baik } \\
(\bar{\pi} 1)\end{array}$ & $\begin{array}{c}\text { Karesalaa } \\
\text { Risgan } \\
\text { (a) }\end{array}$ & $\begin{array}{c}\text { Kerusakaa } \\
\text { Sedang } \\
\text { (113) }\end{array}$ & $\begin{array}{c}\text { Kerusakau } \\
\text { Bernt } \\
\text { (g4) }\end{array}$ \\
\hline Po & 0,078 & 0,058 & 2,650 & 0,381 \\
\hline PI & 0,298 & 0,534 & 0,836 & o.jsi \\
\hline p? & 0.858 & $0,05 s$ & 2023 & 0,023 \\
\hline pj & 0,839 & 0,116 & .023 & 0,023 \\
\hline P4 & 0.812 & 0,168 & 2,649 & 0,031 \\
\hline
\end{tabular}

3) Mesin Type $C$

\begin{tabular}{|c|c|c|c|c|}
\hline \multirow{2}{*}{$\begin{array}{c}\text { Kegiatan } \\
\text { Pemeliharain }\end{array}$} & \multicolumn{4}{|c|}{ Prubabilika } \\
\cline { 2 - 5 } & $\begin{array}{c}\text { Baik } \\
(\pi 1)\end{array}$ & $\begin{array}{c}\text { Kerusakan } \\
\text { Kingan } \\
(\pi 2)\end{array}$ & $\begin{array}{c}\text { Kerusakan } \\
\text { Srdang } \\
(\pi 3)\end{array}$ & $\begin{array}{c}\text { Kerusalkan } \\
\text { Gerat } \\
(\pi 4)\end{array}$ \\
\hline P2 & 0,745 & 0,370 & 0,558 & 0,072 \\
P1 & 0,816 & 0,933 & 0,157 & 0,063 \\
P2 & 6,869 & 0,072 & 0,016 & 0,023 \\
P1 & 0,839 & 0,304 & 0,014 & 0,022 \\
P4 & 0,868 & 0,086 & 0,071 & 0,033 \\
\hline
\end{tabular}

F. Biaya Ekspektasi Perawatan Usulan Paling Minimum

Dari beberapa pemeliharaan mesin yang diusulkan akan di pilih dnegan biaya paling termurah dari biaya ekspetasi yang ada. 


\begin{tabular}{|c|c|c|c|c|c|}
\hline \multirow{2}{*}{ ne } & \multirow{2}{*}{ Merin } & \multicolumn{4}{|c|}{ 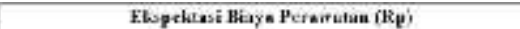 } \\
\hline & & P1 & $\boldsymbol{P}_{2}$ & $\mathbf{F 3}$ & P4 \\
\hline 1 & $\begin{array}{l}\text { Seris } \\
\text { typ* } 2\end{array}$ & $2.55 \%+16$ & $2+5 \times 198$ & 2.450 .253 & 1.956 .555 \\
\hline 2 & $\begin{array}{l}\text { uarin } \\
\text { rypu } 3\end{array}$ & 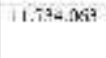 & $70.13+10$ & $7.5 i s .453$ & 12.122 .71 \\
\hline 8 & $\begin{array}{l}\text { serio } \\
\text { Tymo: }\end{array}$ & $807 \times \mathrm{xm}$ & $5+42911$ & $\operatorname{son} x \sin$ & पher: $\mathrm{kw}$ \\
\hline \multicolumn{2}{|c|}{ Tosal Birys } & 22512.352 & 15635.15 & $.8 \div 65.512$ & 23.370 .133 \\
\hline
\end{tabular}

1. Untuk P1 didapat Average Cost ekspektsi senilai Rp. 22.512.352,-

2. Untuk P2 didapat Average Cost ekspektsi senilai Rp. 15.632.119,-

3. Untuk P3 didapat Average Cost ekspektsi senilai Rp. 18.965.512,-

4. Untuk P4 didapat Average Cost ekspektsi senilai Rp. 23.370.138,-

Jadi didapatkan total biaya perawatan paling minimum adalah usulan kebijakan perawatan P2, yaitu sebesar Rp 15.632.119,-

G. Biaya mesin yang ekonomis

Penghematan dari biaya usulan perencanaan pemeliharaan mesin yang minimum (P2) adalah :

$(\mathrm{Rp} \mathrm{36.226.936,-)}-(\mathrm{Rp} 15.632 .119,-)=\mathrm{Rp}$ 20.594.817,-

$(\operatorname{Rp} 20.594 .817,-) /(\operatorname{Rp} 36.226 .936,-) \times 100 \%$ $=56,86 \%$

Biaya pemeliharaan awal Rp 36.226.936,-

Biaya pemeliharaan usulan terminimum $\mathrm{Rp}$ 15.632.119,-

Dari perhitungan biaya pemeliharaan awal - biaya pemeliharaan usulan termurah diperoleh penghematan biaya sebesar $\mathrm{Rp}$ $20.594 .817,-=56,86 \%$

Berdasarkan dari dari data-data yang ada, maka dapat diketahui biaya pemeliharaan metode perusahaan dan metode Markov Chain :

\begin{tabular}{|c|c|c|c|c|}
\hline Jens Mesn & 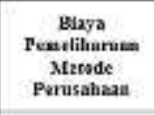 & $\begin{array}{l}\text { RJra rata } \\
\text { waktu } \\
\text { antar } \\
\text { Kotwiakan } \\
\text { \{Lat\}. }\end{array}$ & $\begin{array}{c}\text { Blayz } \\
\text { Pumblihersan } \\
\text { Alerode Slarioar } \\
\text { Chafí }\end{array}$ & $\begin{array}{l}\text { Perencassan } \\
\text { Pemeltharasu }\end{array}$ \\
\hline $\begin{array}{c}\operatorname{Sesin} T y p x \\
\text { i }\end{array}$ & Be 4.375 .304 & 24 & Eq 2.459.458,- & 0,56 Buin \\
\hline $\begin{array}{c}\text { Mesin Type } \\
\text { \& }\end{array}$ & Ro 23.128.855, & 23 & $\mathrm{Rp} T \mathrm{n} 13$ 410:- & 1,52 Bulan \\
\hline $\begin{array}{c}\text { Mesin } T_{y y} \\
c\end{array}$ & $R 98.72272$. & 23 & 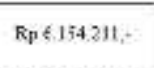 & 0,91 Bukan \\
\hline Jumlah & $R p 3622093 t_{-}-$ & & Rp 13.632 .119$, & \\
\hline
\end{tabular}

\section{KESIMPULAN}

Berdasarkan hasil penelitian dapat ditarik kesimpulan pada type mesin A yang berjumlah
2 mesin, diperlukan waktu 40 menit, untuk type mesin B yang berjumlah 4 mesin memerlukan 80 menit, dan pada type mesin $\mathrm{C}$ yang berjumlah 3 mesin memerlukan waktu sekitar 45 menit untuk tindakan perbaikan dalam satu bulan

Berdasarakan perencanaannya menggunakan metode markovchain maka dapat disimpulkan beberapa hal berikut yaitu, perencanan pemeliharan mesin type $\mathrm{A}$ dan $\mathrm{C}$ dilaksankan setiap satu bulan satukali, dan untuk type mesin $\mathrm{C}$ dilaksanakan satu setengah bulan sekali. Adapun perhtungan Ketika metode markov chain dilaksanakan sesuai rencana maka akan didapatkan total biaya pemeliharann sebesar 15.632.119,- atau dapat menghemat biaya perawatan sekitar 20.594.817,- dari biaya pemeliharaan tana menggunakan metode markovchain yaitu 36.226.936,--.

\section{DAFTAR PUSTAKA}

A. Endo, E. van Leeuwen, and M. Baguelin, "Introduction to particle Markov-chain Monte Carlo for disease dynamics modellers," Epidemics, vol. 29, no. February, p. 100363, 2019, doi: 10.1016/j.epidem.2019.100363.

A. R. Eliyus, J. Alhilman, and Sutrisno, "Estimasi Biaya Maintenance yang Optimal dengan Metode Markov Chain dan Penentuan Umur Mesin serta Jumlah Maintenance Crew yang Optimal dengan metode Life Cycle Cost (Studi Kasus: PT TOA GALVA)," J. Rekayasa Sist. Ind., vol. 1, no. 2, pp. 48-54, 2014.

Bayu Indra Prasetiyo, "Pemeliharaan mesin produksi percetakan menggunakan metode markov chain di CV .Dunia Printig," no. 08660093, pp. 1-147, 2018.

D. Paraforos and H. W. Griepentrog, "Tractor fuel rate modeling and simulation using switching Markov chains on CAN-Bus data," IFAC-PapersOnLine, vol. 52, no. 30, pp. 379-384, 2019, doi: 10.1016/j.ifacol.2019.12.580.

F. KUSUMA, "Penjadwalan Perawatan Mesin Di Industri Menggunakan Metode Markov Chain," 2018.

G. Bacci, G. Bacci, K. G. Larsen, and R. Mardare, "Complete Axiomatization for the Total Variation Distance of Markov 
Chains," Electron. Notes Theor. Comput. Sci., vol. 336, pp. 27-39, 2018, doi: 10.1016/j.entcs.2018.03.014.

L. Qiang and D. Min, "ScienceDirect Research on Complexity Model of Important Product Traceability Efficiency Based on Markov Chain," Procedia Comput. Sci., vol. 166, pp. 456-462, 2020, doi: 10.1016/j.procs.2020.02.065.

M. N. Andriani, F. Firdaniza, and I. Irianingsih, "Reliabilitas Suatu Mesin Menggunakan Rantai Markov (Studi Kasus: Mesin Proofer Di Pabrik Roti Super Jam Banten)," J. Mat. Integr., vol. 13, no. 1, p. 43, 2017, doi: 10.24198/jmi.v13.n1.11414.43-50.

R. P. R and S. N, "Minimizing transmission loss using inspired ant colony optimization and Markov Chain Monte Carlo in underwater WSN environment," J. Ocean Eng. Sci., vol. 4, no. 4, pp. 317-327, 2019, doi: 10.1016/j.joes.2019.05.007.

Rr.Rochmoeljati, "Perencanaan Perawatan Mesin Menggunakan Metode Markov Chain Untuk Meminimumkan Biaya Perawatan," J. Prodi Tek. Ind. FTIUPNV Jatim, pp. 63-74, 2012. Tekmapro: Journal of Industrial Engineering and Management, 8(1). http://www.ejournal.upnjatim.ac.id/inde x.php/tekmapro/article/view/561

T. Shella, "Perencanaan pemeliharaan mesin burner pada tungku peleburan alumunium dengan menggunakan metode markov chain untuk meminimumkan biaya pemeliharaan,"

Z. Wang, J. Zhang, P. Liu, C. Qu, and X. Li, "Driving cycle construction for electric vehicles based on Markov chain and Monte Carlo method: A case study in Beijing," Energy Procedia, vol. 158, pp. 2494-2499, 2019, doi: 10.1016/j.egypro.2019.01.389. 